\title{
A Novel Method for Calculating the Product Category Specific Setpoint Variations for Heat Emitters in EN15316-2
}

\author{
Karl-Villem Võsa ${ }^{\mathrm{a}}$, Andrea Ferrantelli ${ }^{\mathrm{a}}$, Jarek Kurnitski ${ }^{\mathrm{a}}$, \\ ${ }^{a}$ Tallinn University of Technology, Department of Civil Engineering and Architecture, Ehitajate tee 5, 19086 Tallinn, Estonia \\ ${ }^{b}$ Aalto University, Department of Civil Engineering, P.O.Box 12100, 00076 Aalto, Finland
}

\begin{abstract}
Estimating heat emission losses of heating systems is an important task of energy efficiency assessments in buildings. To this aim, the present international standards contain tabulated values for different emitter and control system configurations, without however explaining how to compute the effect of increased setpoint temperatures on the system losses. Moreover, the effects of each component are treated as independent, while e.g. vertical stratification and temperature control of the system are cross-related.

In this paper we attempt to fill this gap by proposing a calculation method to calculate the product category specific setpoint variations for space heating emitters, accounting for the overall heat balance in the enclosure and including the cross-correlations of each component as well.

The emission losses of a heating system are computed using a temperature setpoint variation method that is imposed on annual energy calculations. This complements the procedure presented in the Standard EN15316-2, also providing the possibility to use product-specific values of setpoint variations instead of tabulated values. As the main finding of the study, the calculation process is defined for a European Reference Room, namely for a specific enclosure that allows an accurate and transparent evaluation of the total setpoint variation.

The product-specific values of setpoint variations are calculated from measured vertical stratification and control parameters with an annual simulation model of the European Reference Room. The total setpoint variations were simulated for a set of heat emitters and controllers in order to quantify and compare the energy performance of a new and an old type building located in Strasbourg. We find that the total setpoint variation required to overcome emission losses is up to $2.00{ }^{\circ} \mathrm{C}$ in the old building and $1.20{ }^{\circ} \mathrm{C}$ in the new building, corresponding respectively to an increase in total heating energy usage of up to $22 \%$ and $20 \%$.
\end{abstract}

Keywords: emission efficiency; heat emission; setpoint variation; operative temperature; European Reference Room

\section{Introduction}

Space heating is responsible for a large portion of the total energy demand of buildings worldwide [1, 2]. As it is well known, it indeed consumes a huge amount of resources, both natural and financial [3]. Improving the energy efficiency of heating systems is therefore a priority for the actual building research.

In this context, since heating systems are obviously far from perfect, their heat emission losses need to be taken into account. These are due to non-uniform temperature distribution, heat emitter position and indoor temperature control [4]. More in specific, wall insulation, flow temperatures, heat output of radiators and dynamic effects that are caused by internal heat gains all concur to the emission losses, generating an ensemble of complex dynamical phenomena that were investigated e.g. in $[5,6,7,8]$. In these

\footnotetext{
* Corresponding author

Email address: andrea.ferrantelli@taltech.ee (Andrea Ferrantelli)
} 
studies, dynamic simulations allowed assessing the performance of heating energy systems, although without a specific quantification of the emission losses. A model where this could be possible was recently proposed in [9], where an analytical calculation of the operative temperature in a European reference room allowed to quantify and compare the heat emission losses of different radiator types.

On the experimental side, a comparison of radiators, underfloor and air heating systems with upper distribution was made in [10], where it was shown that the vertical temperature gradient and underfloor structural (embedded) losses are critical for the performance of the different heating systems. The crucial role of the operative temperature was also confirmed. Interestingly, even though the problem of quantifying heat emission losses is clearly important, as of today the dedicated literature remains underdeveloped.

Two methods have previously been used in the standardised assessment of space heating efficiency and emission losses. The so-called German method, based on DIN 18599-6, uses multiplicative part efficiency factors to calculate the necessary primary energy from the net heating energy [11]. To account for all system losses in the heating energy calculation, the French method that is adapted from the national Standard RT2005 ("Réglementation Thermique 2005") uses instead an equivalent increased temperature setpoint [12]. This approach is more dynamic, as the effect of increased setpoint temperature on system losses and overall heating energy use will vary depending on the ambient conditions. Both methods rely on tabulated values for different emitter and control system configurations, with the option of using product-specific values when available.

Remarkably, as of today no standardised method exists for determining these values. The standards do not introduce any procedure highlighting how to measure or calculate these setpoint variation values. Another drawback of both these methods is the underlying assumption that effects of each component in the equations are independent of other components. This is in contrast with experimental evidence, since it is well known that e.g. losses due to vertical stratification and temperature control of the system are in reality cross-dependent (see [10] and references quoted therein). Such a situation is also present in the European Standard EN15316-2:2017 [4], and the existing literature [13, 14, 15] does not fully cover this topic.

In the present paper we attempt to overcome the above limitation, by proposing a calculation method for assessing the product category specific setpoint variations for space heat emitters. The method uses a specific room geometry, similar to the test chamber specified in EN 442-2 [16], and two sets of boundary conditions for old and new building types, which together form a European Reference Room. Validated simulation models are then used to calculate the heating demand in an annual simulation. This is compared to the energy consumption of a reference configuration, and a total setpoint variation is derived for a specific emitter and controller configuration. The simulation model relies on the accurate modelling of the emitter and control system, which get their input parameters from field measurements.

The method is applied on selected emitter configurations that were field-measured in early 2018 at the Tallinn University of Technology, to serve as a proof of concept [17, 18]. We find that the total setpoint variation which is required to offset system losses and maintain the necessary operative temperature in the enclosure is as high as 1.20 and $2.00{ }^{\circ} \mathrm{C}$ for the new and old building types, respectively. This induces up to a 20 and $22 \%$ increase in the annual heating energy consumption.

In the current revision of the European Standard EN15316-2:2017, which reports tabulated values for the emission losses as an equivalent increase in indoor air temperature, only the French method is adopted [19]. Consequently, the content of this paper applies to that method exclusively. The article is structured as follows: in Section 2 we discuss the implementation of heat emission losses in the European Standard, and define our calculation model as well as the yearly simulations setup. In Section 3 we report our results, which are then discussed in depth in Section 4, and we finally draw our conclusions in Section 5.

\section{Methods}

\subsection{Emission losses and efficiency in EN 15316-2}

The European standard EN 15316-2 [4] assesses heat emission efficiency by considering the following aspects in the physical process:

- Vertical temperature variation due to air stratification 


\begin{tabular}{|llll|}
\hline $\mathrm{t}_{\text {in }}$ & supply water temperature $\left[{ }^{\circ} \mathrm{C}\right]$ & & \\
$\mathrm{t}_{\mathrm{out}}$ & return water temperature $\left[{ }^{\circ} \mathrm{C}\right]$ & & \\
$\mathrm{t}_{\text {slab }}$ & average slab temperature $\left[{ }^{\circ} \mathrm{C}\right]$ & & \\
$\mathrm{R}_{\mathrm{t}}$ & virtual resistance $\left[\mathrm{m}^{2} \mathrm{~K} / \mathrm{W}\right]$ & & \\
$\dot{m}$ & mass flow rate $[\mathrm{kg} / \mathrm{s}]$ & subscripts & \\
$\dot{Q}$ & Heat flow rate $[\mathrm{W}]$ & $\mathrm{ctr}$ & control \\
$\mathrm{A}$ & Surface area $\left[\mathrm{m}^{2}\right]$ & $\mathrm{emb}$ & embedded \\
$\mathrm{c}_{\mathrm{p}}$ & isobaric specific heat $[\mathrm{J} /(\mathrm{kgK})]$ & exh & exhaust \\
$\mathrm{K}$ & gain & hydr & hydronics \\
$\mathrm{T}_{\mathrm{i}}$ & integration time $[\mathrm{s}]$ & int,ini & internal, initial \\
$\mathrm{T}_{\mathrm{t}}$ & tracking time $[\mathrm{s}]$ & int,inc & internal, increased \\
$\mathrm{AHU}$ & air handling unit & im & intermittent \\
$\theta$ & air temperature setpoint $\left[{ }^{\circ} \mathrm{C}\right]$ & rad & radiation \\
$\Delta \theta$ & air temperature setpoint variation $\left[{ }^{\circ} \mathrm{C}\right]$ & roomaut & room automatics \\
$\mathrm{t}_{\mathrm{air}}$ & air temperature $\left[{ }^{\circ} \mathrm{C}\right]$ & str & stratification \\
$\mathrm{t}_{\mathrm{op}}$ & operative temperature $\left[{ }^{\circ} \mathrm{C}\right]$ & $\mathrm{N}$ & nominal \\
$\mathrm{t}_{\mathrm{MRT}}$ & mean radiative temperature $\left[{ }^{\circ} \mathrm{C}\right]$ & & \\
$\mathrm{P}$ & proportional & & \\
$\mathrm{PI}$ & proportional integral & & \\
$\mathrm{n}$ & power law exponent & \\
$\mathrm{LMTD}$ & logarithmic mean temperature difference $\left[{ }^{\circ} \mathrm{C}\right]$ & \\
& & & \\
\hline
\end{tabular}

- Accuracy and control variation of the control device

- Embedded losses in the building envelope

- Thermal comfort (operative temperature)

- Hydraulic imbalance

- Possibility of intermittent heating

- Building automatics.

The effect of these components is quantified by means of an equivalent air temperature setpoint that accounts for the extra energy required to overcome system losses in the heat emission system (Figure 1). To each of these components a setpoint variation value is assigned and then added to the initial air temperature setpoint for energy calculation purposes 1 (see also $[19,10]$ ),

$$
\theta_{\text {int }, \text { inc }}=\theta_{\text {int }, i n i}+\Delta \theta_{\text {str }}+\Delta \theta_{c t r}+\Delta \theta_{\text {emb }}+\Delta \theta_{\text {rad }}+\Delta \theta_{\text {im }}+\Delta \theta_{\text {hydr }}+\Delta \theta_{\text {roomaut }} .
$$

This increased setpoint value is then used to calculate the heating energy required in a building. The standard provides tabulated default values for different space heating systems and use scenarios, while also allowing product-specific and different regional default values to be applied. However, the determination of product-specific values is not regulated in the current revision of the EN 15316-2 standard. The draft version of the international standard ISO 52031, which is based on EN 15316-2, specifies a European Reference Room that defines the boundary conditions for the determination of these product values. Nevertheless, it does not provide any calculation method for the setpoint variations. Losses in the heat generation and distribution system are evaluated separately and are not included in this efficiency calculation; all the listed components consider emission in the room exclusively. 


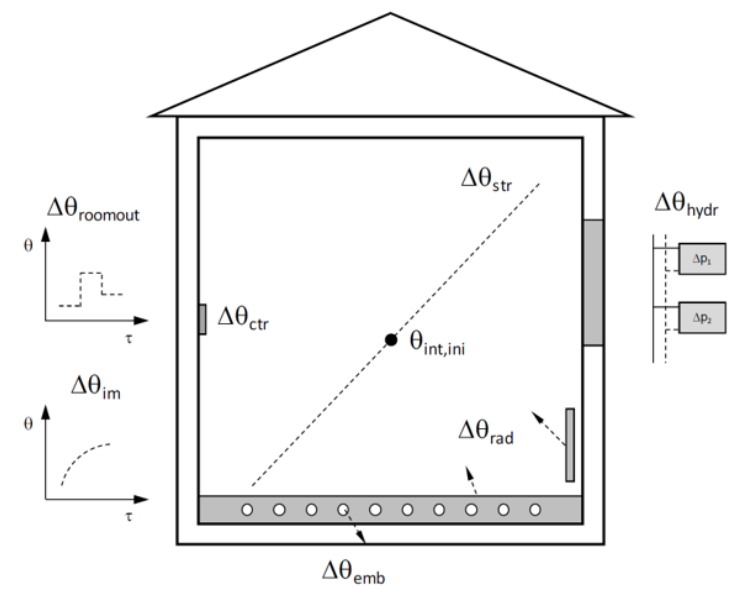

Figure 1: Heat emission losses according to ISO 52031 [20].

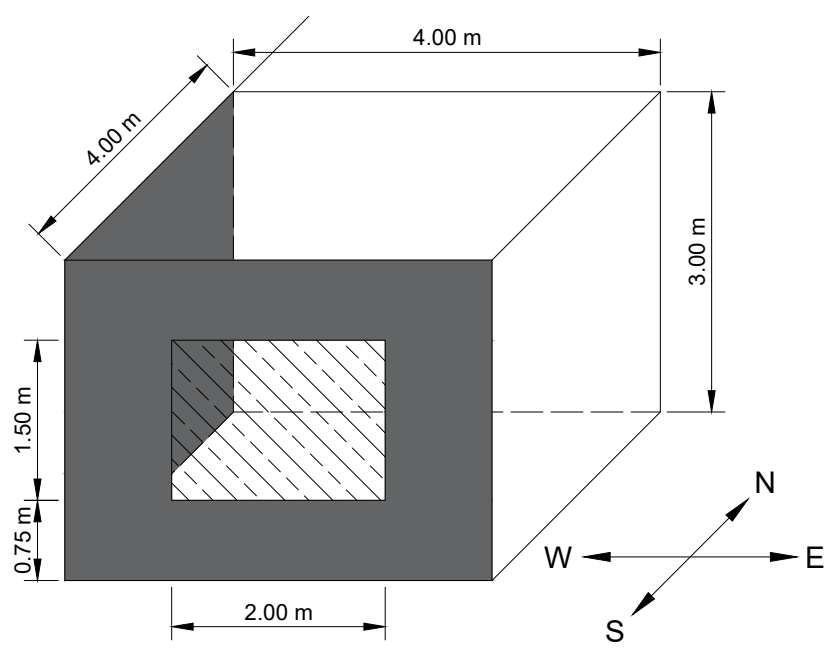

Figure 2: European Reference Room geometry. Shaded surfaces are external walls, rest of the boundary is adiabatic.

\subsection{European Reference Room}

The draft version of ISO 52031 provides two sets of boundary conditions - one each for a newer and an older building. The geometry of the room is shown in Figure 2. This theoretical room is located on the southern facade of a multi-storey building on an intermediate floor. There are either one or two windows with a total size of $3 \mathrm{~m}^{2}$ on the south-facing external wall, while all other bounding surfaces are internal and adiabatic. In such a configuration, the heating demand is a combination of transmission losses through external wall and ventilation supply air heating. A detailed list of imposed boundary conditions is reported in Table 1.

\begin{tabular}{lcc} 
Boundary condition & New building & Old building \\
\hline Windowed area & $3 \mathrm{~m}^{2}$ & $3 \mathrm{~m}^{2}$ \\
Window thermal transmittance & $1.08 \mathrm{~W} /\left(\mathrm{m}^{2} \mathrm{~K}\right)$ & $2.34 \mathrm{~W} /\left(\mathrm{m}^{2} \mathrm{~K}\right)$ \\
Window frame fraction & $30 \%$ & $30 \%$ \\
Window Frame thermal transmittance & $1.20 \mathrm{~W} /\left(\mathrm{m}^{2} \mathrm{~K}\right)$ & $2.00 \mathrm{~W} /\left(\mathrm{m}^{2} \mathrm{~K}\right)$ \\
Window glazing g-value & 0.64 & 0.76 \\
Air change rate & $1.0 h^{-1}$ & $1.0 h^{-1}$ \\
Supply air temperature & $18{ }^{\circ} \mathrm{C}$ & outdoor temperature \\
Heat recovery efficiency & $0.8, t_{\text {exh }} \geq 0^{\circ} \mathrm{C}$ & - \\
Cooling setpoint (air) & $25^{\circ} \mathrm{C}$ & $25{ }^{\circ} \mathrm{C}$ \\
Heating setpoint (operative) & $20^{\circ} \mathrm{C}$ & $20{ }^{\circ} \mathrm{C}$ \\
Window orientation & South & South \\
Internal gains (weekly average) & $3.8 \mathrm{~W} / \mathrm{m}^{2}$ & $3.8 \mathrm{~W} / \mathrm{m}^{2}$ \\
$\quad$ Occupant load (Total) & $2.67 \mathrm{~W} / \mathrm{m}^{2}$ & $2.67 \mathrm{~W} / \mathrm{m}^{2}$ \\
$\quad$ Equipment load & $2.87 \mathrm{~W} / \mathrm{m}^{2}$ & $2.87 \mathrm{~W} / \mathrm{m}^{2}$ \\
Lighting load & $2.87 \mathrm{~W} / \mathrm{m}^{2}$ & $2.87 \mathrm{~W} / \mathrm{m}^{2}$
\end{tabular}

Table 1: European Reference Room boundary conditions.

The internal gains value shown in Table 1 represents the weekly average load as the sum of occupant, equipment and lighting loads. Usage schedules for these loads are shown in Figure 3, while the thermal properties of envelope materials can be found in [9]. 


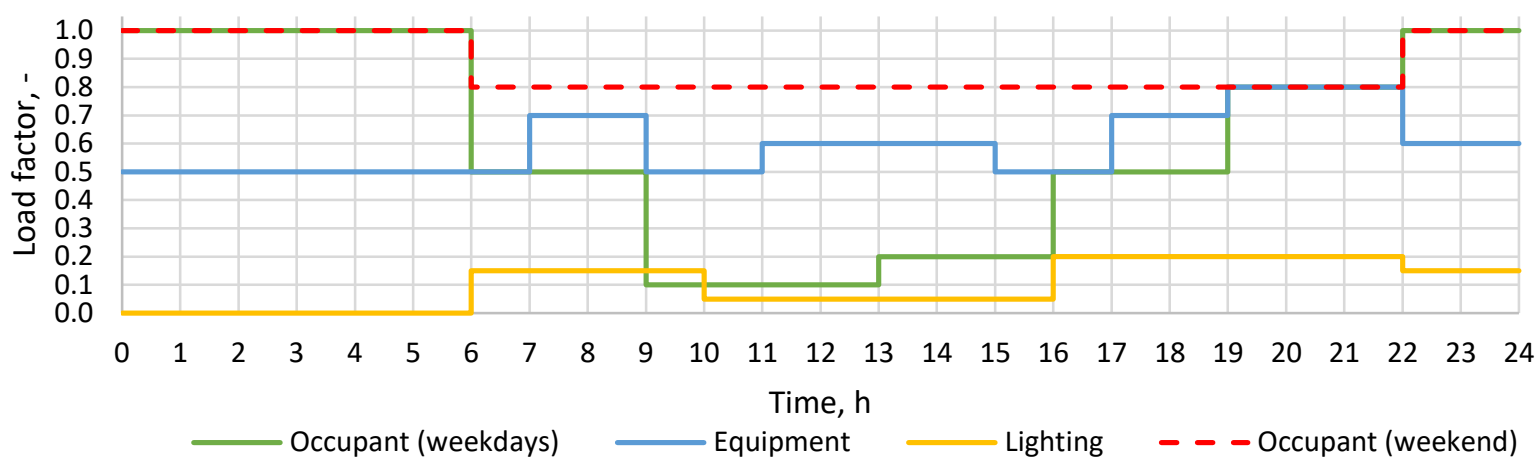

Figure 3: Usage schedules of internal loads.

\subsection{Simulations}

The emission performance of a selection of heat emitters was evaluated with a simulation study according to the developed method. The selection of emitters was based on an experimental study carried out at the Tallinn University of Technology in early 2018, which included the testing of panel radiators, underfloor heating, ceiling panels and air heating $[17,18]$.

Several experimentally obtained parameters, such as the vertical temperature gradient and control parameter values, were used as input for computer simulations performed with IDA ICE ver. 4.8 [21]. The complete list of simulated emitter and controller systems, along with the experimental values being used, is shown in Table 2. Proportional control was not adopted in the experimental study, and typical dead-band values were assumed for the simulation instead. Vertical temperature gradient values of $0.04{ }^{\circ} \mathrm{C} / \mathrm{m}$ for underfloor heating, $0.13{ }^{\circ} \mathrm{C} / \mathrm{m}$ for radiators, $0.36{ }^{\circ} \mathrm{C} / \mathrm{m}$ for air heating and $0.62{ }^{\circ} \mathrm{C} / \mathrm{m}$ for ceiling panels were used.

The annual simulations were run with the IWEC2 climate file for Strasbourg-Entzheim at the geographic location $48.550 \mathrm{~N}, 7.633 \mathrm{E}$ at an elevation of 153 metres [22]. This weather data is visualized in Figure 4. All boundary conditions listed in Table 1 were implemented into the software for the simulations.

\subsection{Emitter models used in IDA ICE}

In each and every simulation discussed in this section, the generation side of the heating systems is ideal, and only room emission is considered in the calculation. Specifically, the CEWATHET model was used to simulate the heat output of the panel radiators. This model uses a power law equation for calculating the heat output,

$$
\dot{Q}=\dot{Q}_{N}\left(\frac{L M T D}{L M T D_{N}}\right)^{n},
$$

where $\mathrm{P}_{\mathrm{N}}$ is the nominal heat output, LMTD is the logarithmic mean temperature difference at calculated supply, return and room temperatures, LMTD $_{\mathrm{N}}$ is the LMTD at nominal supply, return and room temperatures, and $n$ is the power law exponent.

According to EN442-2[16], the nominal heat output, $\mathrm{LMTD}_{\mathrm{N}}$ and power law exponent are performance parameters of the heat emitter. The model uses a uniform surface temperature to calculate the radiation and convection from the front panel surface, while the rest of the heat output is assumed to be a sum of convective heat distributed into the room and transmission losses to the external wall behind the radiator. The ceiling panels are simulated with an identical model. In both cases, the water flow was modulated with a valve according to the control signal from controllers.

The heat emission of the underfloor heating system was simulated with the HCFLOOR model. A virtual resistance $R_{t}$ characterizes the influence of pipe type, spacing, water flow rate and resistance of the conductive layers in the construction, as described in EN 15377-1 [23]. The water-side heat balance is calculated as

$$
\dot{Q}=\dot{m} c_{p}\left(t_{\text {in }}-t_{\text {out }}\right) \text {, }
$$




\begin{tabular}{|c|c|c|c|}
\hline $\begin{array}{l}\text { Heat emitter } \\
\text { type }\end{array}$ & Nominal heat output & Geometry & Control \\
\hline $\begin{array}{l}\text { Panel radia- } \\
\text { tor, new }\end{array}$ & $\begin{array}{l}685 \mathrm{~W} \text { at } 75 / 65^{\circ} \mathrm{C} \text { de- } \\
\text { sign temperatures, } \mathrm{n}= \\
1.2803\end{array}$ & $\begin{array}{l}0.9 \times 0.3 \mathrm{~m}, \text { center- } \\
\text { aligned under the } \\
\text { window at installation } \\
\text { height of } \mathrm{h}=0.15 \mathrm{~m}\end{array}$ & $\begin{array}{l}\mathrm{PI}\left(\mathrm{K}=2.78, \mathrm{~T}_{\mathrm{i}}=1309 \mathrm{~s}, \mathrm{~T}_{\mathrm{t}}=164 \mathrm{~s}\right) \text {, } \\
\text { Proportional }(\mathrm{P} \text {-band }=[0.5,1.0, \\
\left.1.5,2.0]{ }^{\circ} \mathrm{C}\right) \text { and ON/OFF }(\mathrm{DBW} \\
\left.=0.51{ }^{\circ} \mathrm{C}\right)\end{array}$ \\
\hline $\begin{array}{l}\text { Underfloor } \\
\text { heating, new }\end{array}$ & $\begin{array}{l}42 \mathrm{~W} / \mathrm{m}^{2} \text { floor at } 34 / 29 \\
{ }^{\circ} \mathrm{C} \text { design tempera- } \\
\text { tures }\end{array}$ & Covers whole floor area & $\begin{array}{l}\mathrm{PI}\left(\mathrm{K}=3.10, \mathrm{~T}_{\mathrm{i}}=820 \mathrm{~s}, \mathrm{~T}_{\mathrm{t}}=95 \mathrm{~s}\right), \\
\mathrm{ON} / \mathrm{OFF}\left(\mathrm{DBW}=0.78{ }^{\circ} \mathrm{C}\right)\end{array}$ \\
\hline $\begin{array}{l}\text { Ceiling pan- } \\
\text { els, new }\end{array}$ & $\begin{array}{l}418 \mathrm{~W} \text { at } 55 / 45^{\circ} \mathrm{C} \text { de- } \\
\text { sign temperatures }\end{array}$ & $\begin{array}{l}0.6 \times 2.4 \mathrm{~m} \text {, placed at } \\
\text { the centre of the ceiling }\end{array}$ & $\begin{array}{l}\mathrm{PI}\left(\mathrm{K}=3.15, \mathrm{~T}_{\mathrm{i}}=508 \mathrm{~s}, \mathrm{~T}_{\mathrm{t}}=208 \mathrm{~s}\right), \\
\mathrm{ON} / \mathrm{OFF}\left(\mathrm{DBW}=0.78{ }^{\circ} \mathrm{C}\right)\end{array}$ \\
\hline $\begin{array}{l}\text { Air heating, } \\
\text { new }\end{array}$ & $500 \mathrm{~W}$ duct heater & - & Proportional $\left(\mathrm{P}\right.$-band $\left.=0.90{ }^{\circ} \mathrm{C}\right)$ \\
\hline $\begin{array}{l}\text { Panel radia- } \\
\text { tor, old }\end{array}$ & $\begin{array}{l}1817 \mathrm{~W} \text { at } 75 / 65^{\circ} \mathrm{C} \text { de- } \\
\text { sign temperatures, } \mathrm{n}= \\
1.3048\end{array}$ & $\begin{array}{l}2.3 \times 0.45 \mathrm{~m}, \text { center- } \\
\text { aligned under the } \\
\text { window at installation } \\
\text { height of } \mathrm{h}=0.15 \mathrm{~m}\end{array}$ & $\begin{array}{l}\text { PI }\left(\mathrm{K}=2.78, \mathrm{~T}_{\mathrm{i}}=1309 \mathrm{~s}, \mathrm{~T}_{\mathrm{t}}=164 \mathrm{~s}\right) \text {, } \\
\text { Proportional (P-band }=[0.5,1.0, \\
\left.1.5,2.0]{ }^{\circ} \mathrm{C}\right) \text { and ON/OFF }(\mathrm{DBW} \\
\left.=0.51{ }^{\circ} \mathrm{C}\right)\end{array}$ \\
\hline $\begin{array}{l}\text { Underfloor } \\
\text { heating, old }\end{array}$ & $\begin{array}{l}92 \mathrm{~W} / \mathrm{m}^{2} \text { floor at } 43 / 38 \\
{ }^{\circ} \mathrm{C} \text { design tempera- } \\
\text { tures }\end{array}$ & Covers whole floor area & $\begin{array}{l}\mathrm{PI}\left(\mathrm{K}=3.10, \mathrm{~T}_{\mathrm{i}}=820 \mathrm{~s}, \mathrm{~T}_{\mathrm{t}}=95 \mathrm{~s}\right), \\
\mathrm{ON} / \mathrm{OFF}\left(\mathrm{DBW}=0.78{ }^{\circ} \mathrm{C}\right)\end{array}$ \\
\hline $\begin{array}{l}\text { Ceiling pan- } \\
\text { els, old }\end{array}$ & $\begin{array}{l}1904 \mathrm{~W} \text { at } 75 / 65^{\circ} \mathrm{C} \text { de- } \\
\text { sign temperatures }\end{array}$ & $\begin{array}{l}1.2 \times 3.0 \mathrm{~m} \text {, placed at } \\
\text { the centre of the ceiling }\end{array}$ & $\begin{array}{l}\mathrm{PI}\left(\mathrm{K}=3.15, \mathrm{~T}_{\mathrm{i}}=508 \mathrm{~s}, \mathrm{~T}_{\mathrm{t}}=208 \mathrm{~s}\right), \\
\mathrm{ON} / \mathrm{OFF}\left(\mathrm{DBW}=0.78{ }^{\circ} \mathrm{C}\right)\end{array}$ \\
\hline
\end{tabular}

Table 2: Simulated emitter system descriptions.

where $\dot{m}$ is the mass flow rate in the hydronic circuit, $c_{\mathrm{p}}$ is the isobaric specific heat of water and $\mathrm{t}_{\mathrm{in}}, \mathrm{t}_{\mathrm{out}}$ are the supply and return water temperatures in the hydronic system. The return temperature is calculated as

$$
t_{\text {out }}=t_{\text {slab }}+\left(t_{\text {in }}-t_{\text {slab }}\right) \exp \left(-\frac{A}{\dot{m} R_{t} c_{p}}\right),
$$

where $t_{\text {slab }}$ is the average temperature of the conductive slab layer at the piping depth and $A$ is the surface area of the UFH system. Air heating was simulated with an electric heating coil in the supply air stream. The heat output of this coil was modulated according to the control signal from the P-controller. Detailed descriptions of the used emitter and controller models can be found in [24].

\section{Results}

In this section we review our results in their entirety, first discussing those relative to the novel energy balance method here introduced, then reporting on the yearly simulations outcome.

\subsection{Developed method}

Annual energy simulations are used to calculate the total setpoint variation according to the procedure outlined in Figure 5. By comparing the space heater with a baseline configuration with no emission losses, we compute the difference between the according values of annual energy consumption. This represents the heat that is lost by virtue of all emission losses within the system.

Now, since the amount of heating energy that is used to obtain the setpoint temperature with a real heat emitter will be equal to the heating energy used with an idealized heater at a higher temperature setpoint, the difference in setpoint temperatures will be the total setpoint variation.

For the baseline configuration we choose a fully convective point heat source. The heat expelled by convection from this idealized heat source is instantly and uniformly distributed within the room, so that 

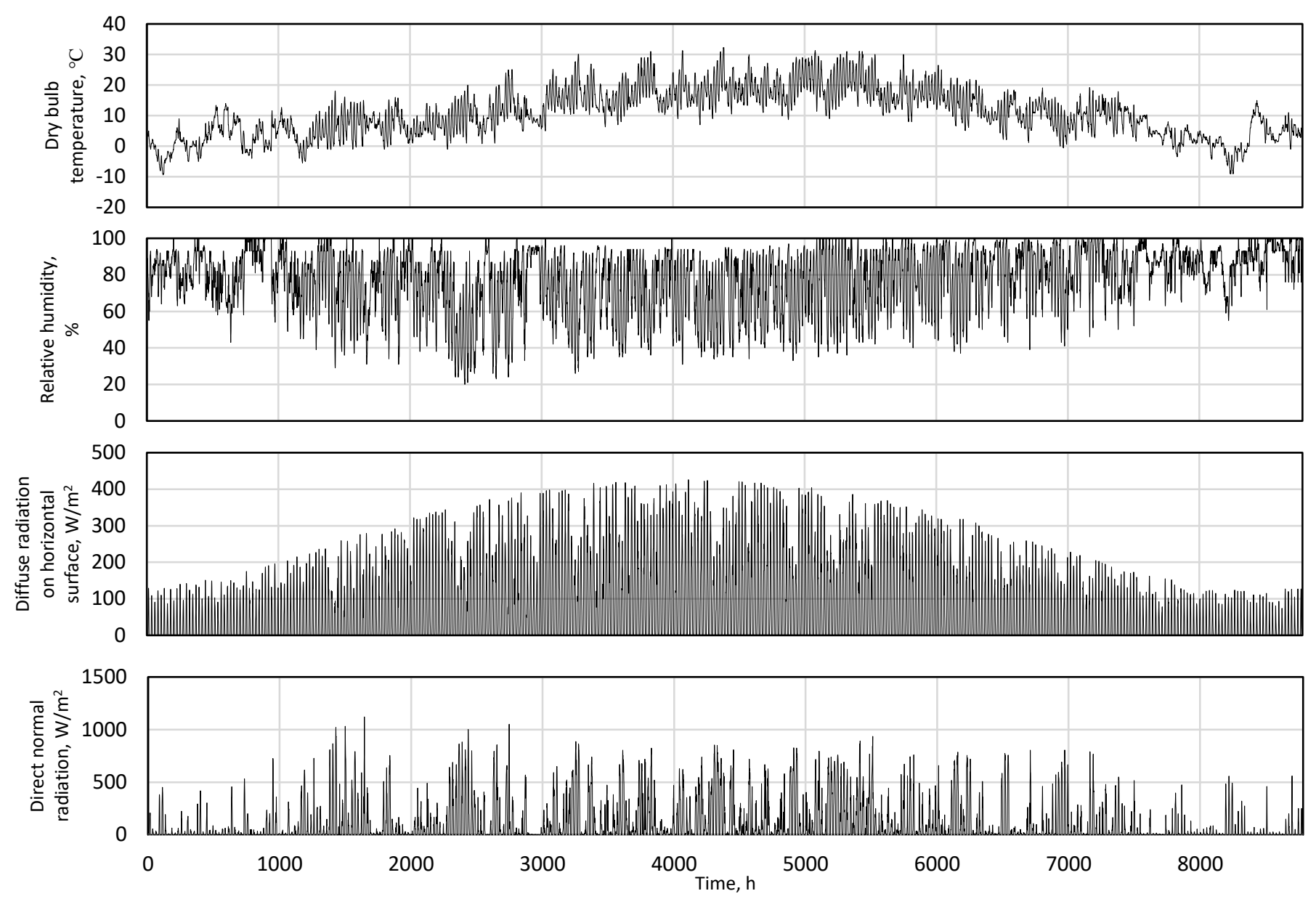

Figure 4: Strasbourg-Entzheim annual weather data. From top to bottom: dry bulb temperature, relative humidity, diffuse radiation on a horizontal surface, direct normal radiation.

no stratification losses occur. The power output of this ideal source is unlimited and responds to the heat demand instantly.

Moreover, to achieve the best control of the system we assume the heat source to have no thermal mass; since it is a point source, embedded losses do not occur either. In other words, such a point heat source represents a case with no inherent heat emission losses. Additionally, this system should be controlled according to operative temperature instead of air temperature, as is the case with real heat emitters.

The operative temperature is defined as the uniform temperature of an enclosure in which an occupant would exchange the same amount of heat by radiation plus convection as in the existing non-uniform environment [25]. In most practical cases where the relative velocity is small $(<0.2 \mathrm{~m} / \mathrm{s})$, or where the difference between mean radiant and air temperature is small $\left(<4^{\circ} \mathrm{C}\right)$, the operative temperature can be calculated with sufficient approximation as the mean value of air and mean radiant temperature (MRT),

$$
t_{o p}=\frac{t_{a}+t_{M R T}}{2} .
$$

For $3 \%$ of the heating period, the operative temperature is allowed to deviate below the setpoint value (Figure 6) as described in [26]. This tolerance avoids unnecessary over-dimensioning of heat emitters due to short periods of unfavourable operating conditions. Such systems would otherwise be operating on a lower partial load which reduces system efficiency. 


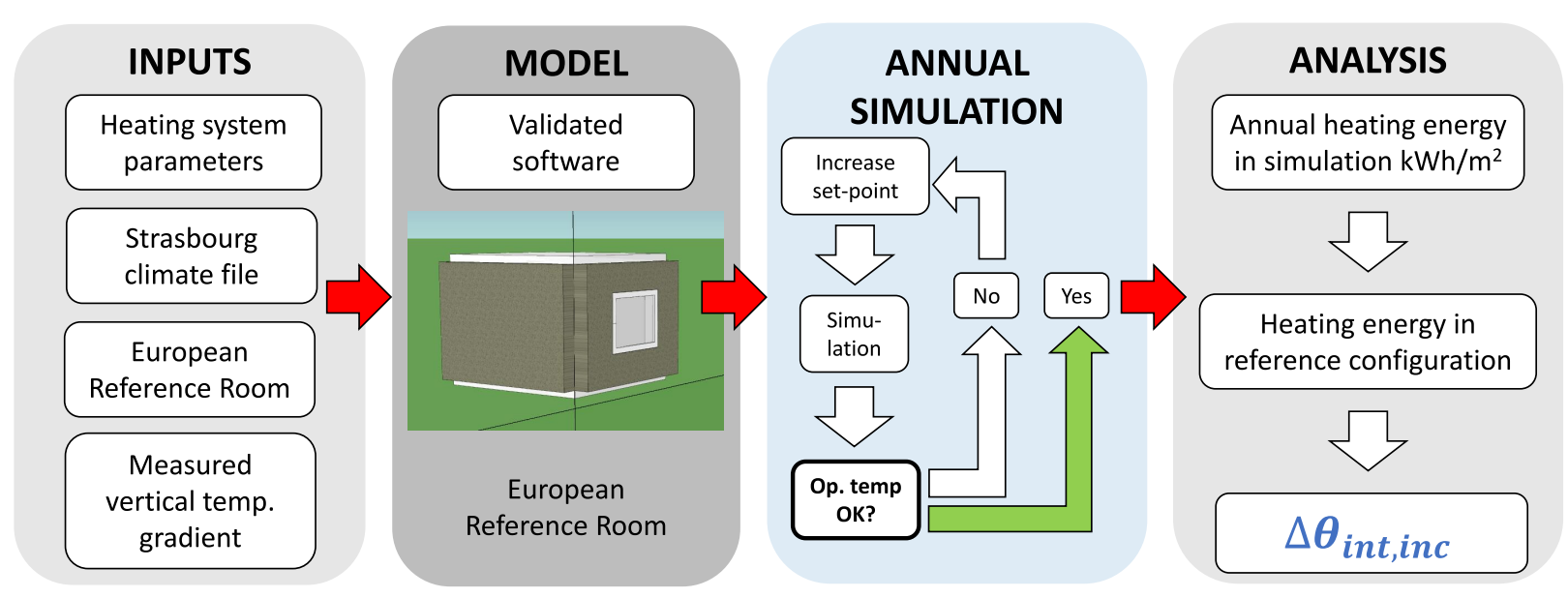

Figure 5: Flow chart of developed method.

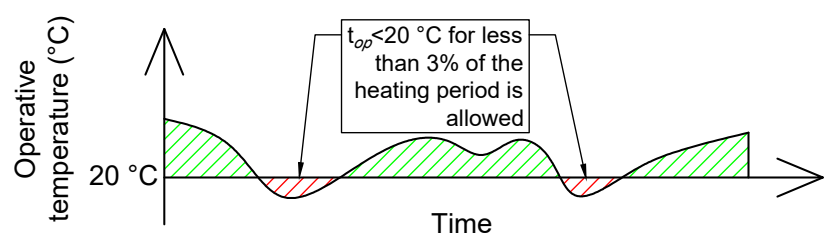

Figure 6: Operative temperature criterion

Considering Eq.(1), the effects of $\Delta \theta_{i m}, \Delta \theta_{\text {hydr }}$ and $\Delta \theta_{\text {roomaut }}$ are undefined in the boundary conditions of the European Reference Room, therefore they should be evaluated separately. Accordingly, the total setpoint variation within the scope of this method takes the following form:

$$
\Delta \theta_{i n t, i n c}=\Delta \theta_{s t r}+\Delta \theta_{c t r}+\Delta \theta_{\text {emb }}+\Delta \theta_{\text {rad }} .
$$

Since the result is achieved from the simulation software, accurate modelling of the emitters and their control systems is required. The simulation software should use input parameters from field measurements, such as nominal heat outputs, controller (valve) performance parameters and vertical air stratification. Validation and accuracy of emitter models are outside the scope of this paper.

\subsection{Annual simulation results}

The main results from the simulation campaign are shown in Table 3. In addition to the heating energy used by the space heaters, the energy used to heat the ventilation supply air is also listed. The sum of these two values represents the total heating energy needed in the room, which is reported in the tables both as an absolute value and as divided by the room floor area. The air temperature setpoints represent the setpoint value needed to satisfy the operative temperature constraint that is shown in Figure 6, when it is subjected to the control parameters in Table 2. Such temperature itself is not directly used in the evaluation of the total setpoint variation, because the direct result of this setpoint is instead the amount of required heating energy. The annual heating energy was compared to the demand of the baseline configuration at different air temperature setpoints, as illustrated in Figures $7 \mathrm{a}$ and $7 \mathrm{~b}$.

Such a comparison was needed to quantify the total setpoint variation, whose values ranged from 0.14 to $1.20^{\circ} \mathrm{C}$ in the new building and from 0.38 to $2.00{ }^{\circ} \mathrm{C}$ in the old building. In both cases, the PI controller outperformed the proportional controller, with the simple ON/OFF control exhibiting the worst performance. The annual heating energy demand in the new building type is an order of magnitude smaller than in the old building type. Supply air heating accounted for $8-22 \%$ of the total heating energy used in the new building. 
Lack of supply air heating and heat recovery in the old building means that cold outdoor air is heated up by the heat emitter directly.

\begin{tabular}{|c|c|c|c|c|c|c|c|}
\hline \multirow{3}{*}{ Building type } & \multirow{3}{*}{ Heat emitter } & \multirow{3}{*}{$\begin{array}{l}\text { Air temperature } \\
\text { setpoint } \\
{ }^{\circ} \mathrm{C}\end{array}$} & \multicolumn{4}{|c|}{ Annual heating energy used } & \multirow{3}{*}{$\begin{array}{c}\Delta \theta_{\text {int }, \text { inc }} \\
{ }^{\circ} \mathrm{C}\end{array}$} \\
\hline & & & Emitter & AHU & Emitt & $+\mathrm{AHU}$ & \\
\hline & & & kWh & $\mathrm{kWh}$ & $\mathrm{kWh}$ & $\mathrm{kWh} / \mathrm{m}^{2}$ & \\
\hline \multirow{11}{*}{ New } & Ceiling ON/OFF & 20.60 & 298.60 & 25.61 & 324.21 & 20.26 & 1.20 \\
\hline & UFH ON/OFF & 20.40 & 264.10 & 42.55 & 306.65 & 19.17 & 0.85 \\
\hline & Air heating & 20.30 & 0.00 & 303.60 & 303.60 & 18.98 & 0.78 \\
\hline & $\mathrm{Rad} 21 \mathrm{ON} / \mathrm{OFF}$ & 20.47 & 257.30 & 44.25 & 301.55 & 18.85 & 0.74 \\
\hline & Ceiling PI & 20.24 & 257.70 & 31.37 & 289.07 & 18.07 & 0.48 \\
\hline & Rad 21 P 2.0 & 19.83 & 243.70 & 44.97 & 288.67 & 18.04 & 0.47 \\
\hline & $\operatorname{Rad} 21 \mathrm{P} 1.5$ & 19.97 & 241.60 & 45.69 & 287.29 & 17.96 & 0.44 \\
\hline & $\operatorname{Rad} 21 \mathrm{P} 1.0$ & 20.11 & 239.50 & 46.45 & 285.95 & 17.87 & 0.41 \\
\hline & $\operatorname{Rad} 21 \mathrm{P} 0.5$ & 20.26 & 238.60 & 47.01 & 285.61 & 17.85 & 0.40 \\
\hline & Rad 21 PI & 20.40 & 235.20 & 47.65 & 282.85 & 17.68 & 0.34 \\
\hline & UFH PI & 20.03 & 214.40 & 59.58 & 273.98 & 17.12 & 0.14 \\
\hline \multirow{10}{*}{ Old } & Ceiling ON/OFF & 20.30 & 2697.00 & 0.00 & 2697.00 & 168.56 & 2.00 \\
\hline & $\operatorname{Rad} 21 \mathrm{ON} / \mathrm{OFF}$ & 20.68 & 2436.60 & 0.00 & 2436.60 & 152.29 & 0.98 \\
\hline & $\operatorname{Rad} 21$ P 2.0 & 20.55 & 2431.70 & 0.00 & 2431.70 & 151.98 & 0.96 \\
\hline & $\operatorname{Rad} 21$ P 1.5 & 20.57 & 2409.90 & 0.00 & 2409.90 & 150.62 & 0.88 \\
\hline & $\mathrm{UFH} \mathrm{ON} / \mathrm{OFF}$ & 20.04 & 2403.00 & 0.00 & 2403.00 & 150.19 & 0.85 \\
\hline & $\operatorname{Rad} 21 \mathrm{P} 1.0$ & 20.58 & 2385.60 & 0.00 & 2385.60 & 149.10 & 0.78 \\
\hline & $\operatorname{Rad} 21 \mathrm{P} 0.5$ & 20.60 & 2365.30 & 0.00 & 2365.30 & 147.83 & 0.69 \\
\hline & Ceiling PI & 19.96 & 2345.20 & 0.00 & 2345.20 & 146.58 & 0.61 \\
\hline & Rad 21 PI & 20.62 & 2341.30 & 0.00 & 2341.30 & 146.33 & 0.60 \\
\hline & UFH PI & 19.81 & 2287.40 & 0.00 & 2287.40 & 142.96 & 0.38 \\
\hline
\end{tabular}

Table 3: Detailed simulation results.

To enable further analysis, air and operative temperature duration graphs are shown in Figures 8 and 9. The effect of different control systems is clearly visible when observing the air temperatures during the heating period. Underfloor heating with PI control performed the best in the new building, the air temperature closely followed the operative temperature and thus the operative temperature setpoint. In the old building, the offset between operative and air temperature was greater for all systems.

\section{Discussion}

According to the current implementation, the EN15316 standard fails to account for different building specifications. Only an indirect evaluation is provided, in the sense that tabulated values provide limited selections that might correspond to a building of a certain era (e.g. older buildings generally have inferior control for space temperature regulation, but not necessarily in the case of refurbished buildings).

Furthermore, the component-wise assessment of emission efficiency presented in Eq.(1) poses a problem from both theoretical and experimental viewpoints. Cross-dependencies between most of the loss components do exist indeed, making it impossible to evaluate each individual component separately. For example, heat recovery in modern ventilation units greatly reduces the differences in emission losses between different emitter systems. Extra heat is emitted into the room as a result of non-uniform distribution of air temperature due to imperfect control, together with vertical stratification and a higher air-temperature setpoint due to thermal comfort requirements. Such free energy can be largely recovered in the heat air handling unit (a process that is limited only by the heat recovery efficiency), thus reducing the energy required to heat the supply air, which itself contributes to the total heating energy used. This explains the great differences in the annual heating energy used in the heating coil of the AHU, as seen in Table 3. 


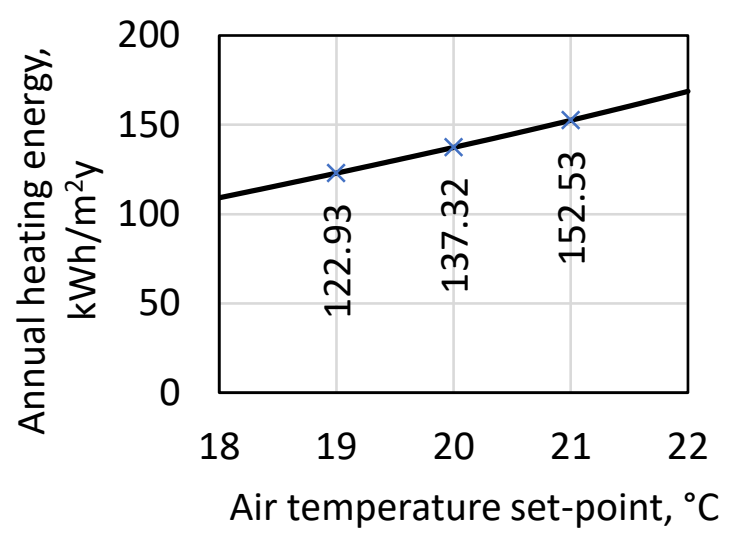

(a) Old building.

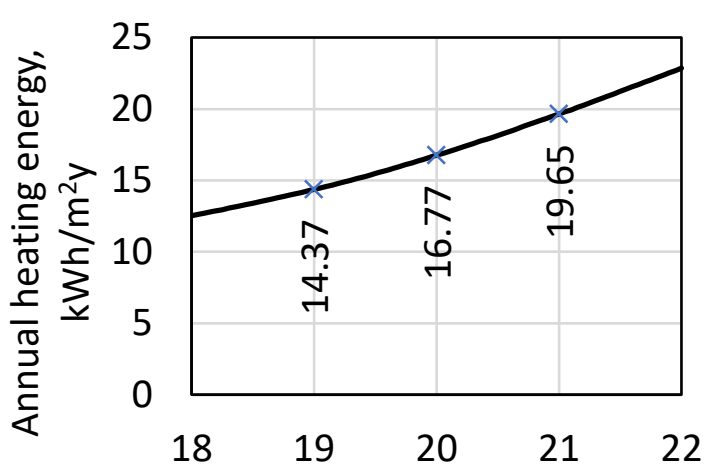

Air temperature set-point, ${ }^{\circ} \mathrm{C}$

(b) New building.

Figure 7: Annual heating energy usage of reference configuration.

ত
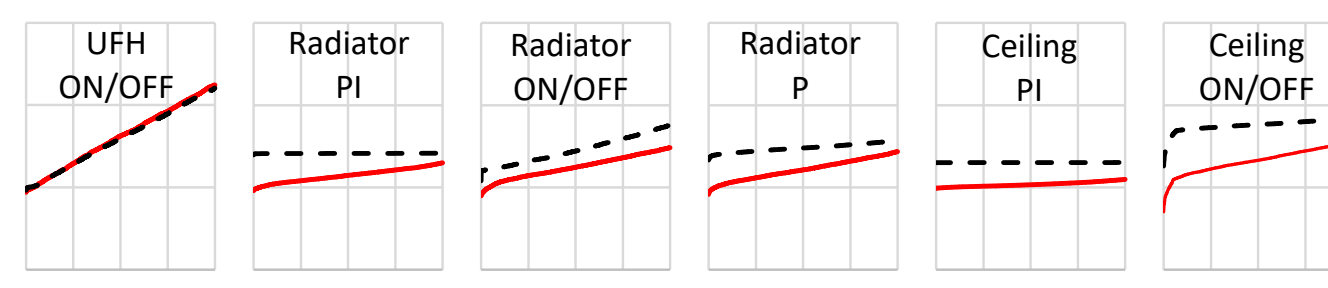

Air heating

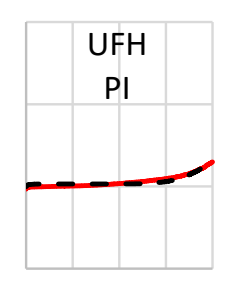

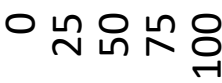

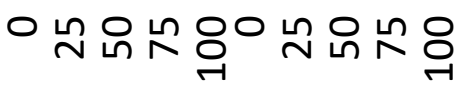

Duration of heating period [\%]

Operative temperature

- - - - - - - Air temperature

Figure 8: Air and operative temperature duration graphs - new building.

西
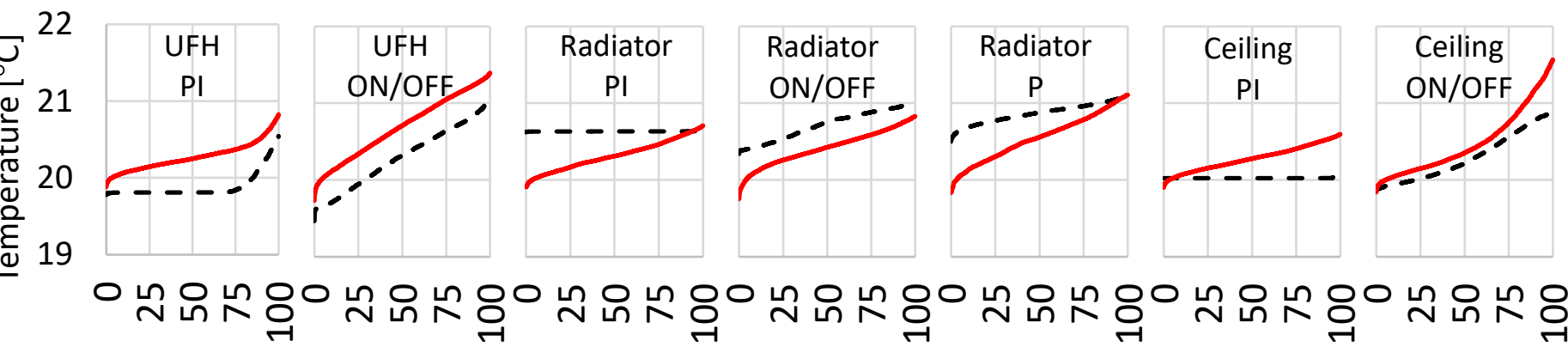

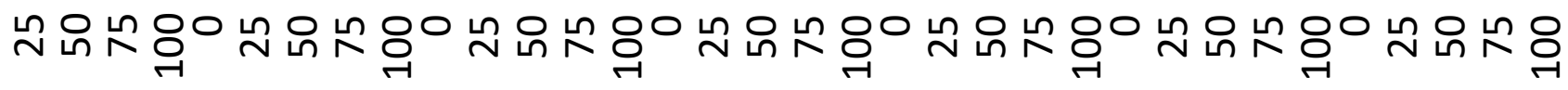

Duration of heating period [\%]

\section{Operative temperature}

------ Air temperature

Figure 9: Air and operative temperature duration graphs - old building. 
In Figures $7 \mathrm{a}$ and $7 \mathrm{~b}$, the correlation between air temperature setpoint and annual heating energy is non-linear. Each additional increase in the temperature setpoint will then have a larger effect on the energy usage. In other words, if each setpoint increment is evaluated separately and later summed up to achieve the total setpoint variation, the energy used will be over-estimated.

Based on these arguments, we recommend that the setpoint variations should be evaluated as a single total setpoint variation instead. Our developed method uses a common set of boundary conditions in the European Reference Room to derive this value from annual simulations. Employing two subsets of boundary conditions (for modern as well as older buildings) eliminates the ambiguity under which the emission loss components are evaluated, providing at the same time a common platform to compare emitter emission efficiency under standardised conditions.

Understandably, these boundary conditions cannot reflect the operating conditions in every geographical region in Europe, but rather constitute average European operating conditions. To this end, we also suggest that national versions of the standard may impose a different set of boundary conditions, to best represent the climate and construction materials used in the region under question.

The three components omitted in the total setpoint variation in Eq.(6) are better suited to be evaluated separately from room emission efficiency. Namely, the extra losses due to hydraulic imbalances and building automation systems are part of a system that is larger than a single space and is not uniquely defined within the European Reference Room specification.

On the other hand, intermittent heating should be implemented directly within the simulation, in order to capture its effect on the annual energy use rather than trying to evaluate it indirectly. When considering energy performance certificates of buildings, intermittent may not even be allowed, as is the case in some Nordic countries such as Finland and Estonia, where the required setpoint has to be maintained at all times.

Observing the results from the simulation study, the effect of the control system was the greatest for underfloor heating. This is the expected result, as this system has the highest thermal mass and therefore the greatest thermal inertia. This is more evident in the new building, where the deviations in the heating demand are relatively higher. On the other hand, underfloor heating systems are known to provide the same level of thermal comfort at a lower air temperature when compared to other systems, due to a higher mean radiant temperature $[5,10]$. This explains why the UFH with PI control has the lowest total setpoint variation in both building types. Furthermore, the air temperature and operative temperature duration curves in Figures 8 and 9 are almost identical for the underfloor heating in the case of new building, resulting in only minimal heat losses due to the room being controlled by air temperature in relation to the operative temperature criterion.

\section{Conclusions}

In this study, a method was developed to calculate product-specific total setpoint variations to be used in the EN15316-2 standard. This method uses the definition, specification and boundary conditions of a European Reference Room included in the ISO/DIS 52031 standard, along with specific criteria that were developed to obtain the total setpoint variation from annual simulations. The main criterion requires an operative temperature of $20^{\circ} \mathrm{C}$ to be maintained within the room for at least $97 \%$ of the heating period duration. The air temperature setpoint in the simulation is increased until this constraint is satisfied, and the annual heating energy use in the simulation is then compared to the consumption of a lossless reference configuration. Crucially, this comparison allows achieving a total setpoint variation.

This method was applied to a selected set of emitter and controller configurations, which were previously measured in an experimental study including panel radiators, underfloor heating, ceiling panels and air heating with PI, Proportional and ON/OFF controls. Relevant parameters such as measured vertical stratification, controller parameters and nominal heat outputs were used as input for the model in the annual simulations. Total setpoint variations of up to 1.20 and $2.00{ }^{\circ} \mathrm{C}$ were obtained for the new and old building definitions in the Strasbourg climate. This resulted respectively in 20 and $22 \%$ increases in annual heating energy consumption due to system losses. Overall, the method provides a reliable, accurate and transparent way to calculate the total setpoint variation for specific product configurations. 
We recommend this procedure to quantify the total setpoint variation since it better represents the effect of real system losses, if compared to an individual assessment of each component. The European Reference Room definition provides standardized conditions to objectively compare the heat emission efficiency over a wide variety of configurations. National versions of the standard could define a different set of boundary conditions to best characterize the emission efficiency in their local climate and building practices.

\section{Acknowledgement}

This research was supported by the Association of the European Heating Industry EHI, with member companies Irsap Spa, REHAU AG + Co, Stelrad Radiator Group Limited, Uponor Corporation, Vasco Group, Wavin B.V., Rettig Austria and Zehnder Group International AG. We also wish to acknowledge the Estonian Centre of Excellence in Zero Energy and Resource Efficient Smart Buildings and Districts ZEBE, grant 2014-2020.4.01.15-0016, funded by the European Regional Development Fund.

\section{References}

[1] S. Serrano, D. Ürge Vorsatz, C. Barreneche, A. Palacios, L. F. Cabeza, Heating and cooling energy trends and drivers in europe, Energy 119 (2017) 425 - 434. doi:https://doi.org/10.1016/j.energy.2016.12.080.

[2] D. D'Agostino, B. Cuniberti, P. Bertoldi, Data on european non-residential buildings, Data in Brief 14 (2017) 759 - 762. doi:https://doi.org/10.1016/j.dib.2017.08.043.

[3] M. Lu, J. H. Lai, Building energy: a review on consumptions, policies, rating schemes and standards, Energy Procedia 158 (2019) 3633 - 3638, innovative Solutions for Energy Transitions. doi:https://doi.org/10.1016/j.egypro.2019.01.899.

[4] Comité Européen de Normalisation, European Standard EN 15316-2:2017. Energy performance of buildings. Method for calculation of system energy requirements and system efficiencies. Space emission systems (heating and cooling), Module M3-5, M4-5., Tech. rep., CEN, Bruxelles, BE (2017).

[5] A. Hasan, J. Kurnitski, K. Jokiranta, A combined low temperature water heating system consisting of radiators and floor heating, Energy and Buildings 41 (5) (2009) 470 - 479. doi:https://doi.org/10.1016/j.enbuild.2008.11.016.

[6] G. Sevilgen, M. Kilic, Numerical analysis of air flow, heat transfer, moisture transport and thermal comfort in a room heated by two-panel radiators, Energy and Buildings 43 (1) (2011) 137 - 146. doi:https://doi.org/10.1016/j.enbuild.2010.08.034.

[7] E. Zanchini, A. Jahanbin, Effects of the temperature distribution on the thermal resistance of double u-tube borehole heat exchangers, Geothermics 71 (Supplement C) (2018) 46 - 54. doi:https://doi.org/10.1016/j.geothermics.2017.07.009.

[8] A. Robinson, A thermal model for energy loss through walls behind radiators, Energy and Buildings 127 (Supplement C) (2016) 370 - 381. doi:https://doi.org/10.1016/j.enbuild.2016.05.086.

[9] K.-V. Võsa, A. Ferrantelli, J. Kurnitski, A combined analytical model for increasing the accuracy of heat emission predictions in rooms heated by radiators, Journal of Building Engineering 23 (2019) 291 - 300. doi:https://doi.org/10.1016/j.jobe.2019.02.009.

[10] M. Maivel, A. Ferrantelli, J. Kurnitski, Experimental determination of radiator, underfloor and air heating emission losses due to stratification and operative temperature variations, Energy and Buildings 166 (2018) $220-228$. doi:https://doi.org/10.1016/j.enbuild.2018.01.061.

[11] D. I. fur Normung, DIN V 18599-6:2018-09 - Energy Efficiency of Buildings - Calculation of the Net, Final and Primary Energy Demand for Heating, Cooling, Ventilation, Domestic Hot Water and Lighting. (2018).

[12] J.-b. Videau, J.-m. Alessandrini, B. Haas, C. Pelé, J.-r. Millet, P. Jallet, L. Reynier, E. Fleury, An introduction to the development of the french energy regulation indicators and their calculation methods, in: CLIMA $2013,2013$.

[13] B. W. Olesen, M. de Carli, Calculation of the yearly energy performance of heating systems based on the european building energy directive and related cen standards, Energy and Buildings 43 (5) (2011) 1040 - 1050, tackling building energy consumption challenges - Special Issue of ISHVAC 2009, Nanjing, China. doi:https://doi.org/10.1016/j.enbuild.2010.10.009.

[14] J. Seifert, M. Knorr, A. Meinzenbach, F. Bitter, N. Gregersen, T. Krogh, "review of thermostatic control valves in the european standardization system of the en 15316-2/en 215", Energy and Buildings 125 (2016) 55 - 65. doi:https://doi.org/10.1016/j.enbuild.2016.04.066.

[15] C. Brembilla, M. Vuolle, R. Östin, T. Olofsson, Practical support for evaluating efficiency factors of a space heating system in cold climates, Energy Efficiency 10 (5) (2017) 1253-1267. doi:10.1007/s12053-017-9506-7.

[16] Comité Européen de Normalisation, EN 442-2:2014, Radiators and convectors - Part 2: Test methods and rating (2014).

[17] K.-V. Võsa, A. Ferrantelli, J. Kurnitski, Annual performance analysis of heat emission in radiator and underfloor heating systems in the European reference room, in: E3S Web of Conferences, Vol. 111, 2019. doi:10.1051/e3sconf/201911104009.

[18] K.-V. Võsa, A. Ferrantelli, J. Kurnitski, Experimental study of radiator, underfloor, ceiling and air heater systems heat emission performance in TUT nZEB test facility, in: E3S Web of Conferences, Vol. 111, 2019. doi:10.1051/e3sconf/201911104005.

[19] International Organization for Standardization, ISO 15316-2:2017. Energy performance of buildings - Method for calculation of system energy requirements and system efficiencies - Part 2: Space emission systems (heating and cooling), Module M3-5, M4-5 (2017). 
[20] International Organization for Standardization, ISO 52031. Energy performance of buildings - Method for calculation of system energy requirements and system efficiencies - Space emission systems (heating and cooling). Pending.

[21] IDA ICE - Indoor Climate and Energy (2013).

[22] American Society of Heating Refrigerating and Air-Conditioning Engineers, International Weather Files For Energy Calculations 2.0 (IWEC2) (2012).

[23] Comité Européen de Normalisation, En 15377-1, heating systems in buildings - design of embedded water based surface heating and cooling systems - part 1: Determination of the design heating and cooling capacity (2008).

[24] A. Bring, P. Sahlin, M. Vuolle, Models for building indoor climate and energy simulation, Journal of Research and Development 21 (1999) 350-359. https://www.equa.se/dncenter/T22Brep.pdf.

[25] I. O. for Standardization, ISO 7726:1998 Ergonomics of the thermal environment - Instruments for measuring physical quantities (1998).

[26] Comité Européen de Normalisation, Energy performance of buildings - Ventilation for buildings - Part 2: Interpretation of the requirements in EN 16798-1 - Indoor environmental input parameters for design and assessment of energy performance of buildings addressing indoor air quality, thermal environment, lighting and acoustics (Module M1-6) (2019). 